\title{
Building Library Community Through Social Media
}

ABSTRACT

In this article academic librarians present and analyze a model for community-building through social media. Findings demonstrate the importance of strategy and interactivity via social media for generating new connections with library users. Details of this research include successful guidelines for building community and developing engagement online with social media. By applying intentional social media practices, the researchers' Twitter user community grew 100 percent in one year, with a corresponding 275 percent increase in user interactions. Using a community analysis approach, this research demonstrates that the principles of personality and interactivity can lead to community formation for targeted user groups. Discussion includes the strategies and research approaches that were employed to build, study, and understand user community, including user-type analysis and action-object mapping. From this research a picture of the library as a member of an active academic community comes into focus.

\section{INTRODUCTION}

This paper describes an academic library's approach to building community through Twitter. Much of the literature offers guidance to libraries on approaches to using social media as a marketing tool. The research presented here reframes that conversation to explore the role of social media as it relates to building community. The researchers' university library formed a social media group and implemented a social media guide to bring an intentional, personality-rich, and interaction-driven approach to its social media activity. Quantitative analyses reveal a significant shift and increase in Twitter follower population and interactions, and suggest promising opportunities for social media to strengthen the library's ties with academic communities.

\section{LITERATURE REVIEW}

Research in libraries has long brought a critical analysis to the value, purpose, and practical usage of social media. Glazer asked of library Facebook usage, "Clever outreach or costly diversion?"1 Three years later, Glazer presented a more developed perspective on Facebook metrics and the nature of online engagement, but social media was still described as "puzzling and poorly defined." 2 Vucovich et al. furthermore notes that "the usefulness of [social networking tools] has often proven elusive, and evaluating their impact is even harder to grasp in library settings."3

Scott W. H. Young (swyoung@montana.edu) is Digital Initiatives Librarian and Doralyn Rossmann (doralyn@montana.edu) is Head of Collection Development, Montana State University Library, Bozeman. 
Li and Li similarly observe that there "seems to be some confusion regarding what exactly social media is." 4 Social media has been experimented with and identified variously as a tool for enhancing the image of libraries, ${ }^{5}$ as a digital listening post, ${ }^{6}$ or as an intelligence gathering tool. ${ }^{7}$ With such a variety of perspectives and approaches, the discussion around social media in libraries has been somewhat disjointed.

If there is a common thread through library social media research, however, it ties together the broadcast-based promotion and marketing of library resources and services, what Li calls "the most notable achievement of many libraries that have adopted social media." 8 This particularly common approach has been thoroughly examined.9,10,11,12,13,14,15 In evaluating the use of Facebook at Western Michigan University's Waldo Library, Sachs, Eckel, and Langan found that promotion and marketing was the only "truly successful" use for social media. ${ }^{16} \mathrm{~A}$ survey of Estonian librarians revealed that Facebook "is being used mainly for announcements; it is reduplicating libraries' web site[s]. Interestingly librarians don't feel a reason to change anything or to do something differently." 17 With this widespread approach to social media, much of the library literature is predominated by exploratory descriptions of current usage and implementation methods under the banner of promoting resources by meeting users where they are on social media. $18,19,20,21,22,23,24,25,26,27$ This research is effective at describing how social media is used, but it often does not extend the discussion to address the more difficult and valuable question of why social media is used.

The literature of library science has not yet developed a significant body of research around the practice of social media beyond the broadcast-driven, how-to focus on marketing, promotion, and public-relations announcements. This deficiency was recognized by Saw, who studied social networking preferences of international and domestic Australian students, concluding "to date, the majority of libraries that use social networking have used it as a marketing and promotional medium to push out information and announcements. Our survey results strongly suggest that libraries need to further exploit the strengths of different social networking sites." 28 From this strong emphasis on marketing and best practices emerges an opportunity to examine social media from another perspective-community building-which may represent an untapped strength of social networking sites for libraries.

While research in library and information science has predominantly developed around social media as marketing resource, a small subset has begun to investigate the community-building capabilities of social media. ${ }^{29,30,31,32}$ By making users feel connected to a community and increasing their knowledge of other members, "sites such as Facebook can foster norms of reciprocity and trust and, therefore, create opportunities for collective action." ${ }^{33}$ Lee, Yen, and Hsiao studied the value of interaction and information sharing on social media: "A sense of belonging is achieved when a friend replies to or 'Likes' a post on Facebook." 34 Lee found that Facebook users perceived real-world social value from shared trust and shared vision developed and expressed through information-sharing on social media. Research from Oh, Ozkaya, and 
LaRose indicated that users who engaged in a certain quality of social media interactivity perceived an enhanced sense of community and life satisfaction. ${ }^{35}$

Broader discussion of social media as a tool for community-building has been advanced within the context of political activity, where social media is identified as a method for organizing civic action and revolutionary protests. ${ }^{36,37,38}$ Related research focuses on the online social connections and "virtual communities" developed around common interests such as religion, ${ }^{39}$ health, ${ }^{40}$ education, ${ }^{41}$ social interests and norms, ${ }^{42}$ politics, ${ }^{43}$ web-video sharing, ${ }^{44}$ and reading. ${ }^{45}$ In these analyses, social media is framed as an online instrument utilized to draw together offline persons. Hofer notes that communities formed online through social media activity can generate a sense of "online bonding social capital." 46 Further marking the online/offline boundary, research from Grieve et al. investigates the value of social connectedness in online contexts, suggesting that social connectedness on Facebook "is a distinct construct from face-to-face social connectedness." 47 Grieve et al. acknowledges that the research design was predicated on the assumptive existence of an online/offline divide, noting "it is possible that such a separation does not exist." 48

Around this online/offline separation has developed "digital dualism," a theoretical approach that interrogates the false boundaries and contrasts between an online world as distinct from an offline world. ${ }^{49,50}$ Sociologist Zeynep Tufekci expressed this concisely: "In fact, the Internet is not $a$ world; it's part of the world." 51 A central characteristic of community-building through social media is that the "online" experience is so connected and interwoven with the "offline" experience as to create a single seamless experience. This concept is related to a foundational study from Ellison, Steinfield, and Lampe, who identified Facebook as a valuable subject of research because of its "heavy usage patterns and technological capacities that bridge online and offline connections." 52 They conclude, "Online social network sites may play a role different from that described in early literature on virtual communities. Online interactions do not necessarily remove people from their offline world but may indeed be used to support relationships." 53

This paper builds on existing online community research while drawing on the critical theory of "digital dualism" to argue that communities built through social media do not reside in a separate "online" space, but rather are one element of a much more significant and valuable form of holistic connectedness. Our research represents a further step in shifting the focus of library social media research and practice from marketing to community building, recasting library-led social media as a tool that enables users to join together and share in the commonalities of research, learning, and the university community. As library social media practice advances within the framework of community, it moves from a one-dimensional online broadcast platform to a multidimensional socially connected space that creates value for both the library and library users.

\section{METHOD}

In May 2012, Montana State University Library convened a social media group (SMG) to guide our 
social media activity. The formation of SMG marked an important shift in our social media activity and was crucial in building a strategic and programmatic focus around social media. This internal committee, comprising three librarians and one library staff member, aimed to build a community of student participants around the Twitter platform. SMG then created a social media guide to provide structure for our social media program. This guide outlines eight principal components of social media activity (see table 1 ).

\begin{tabular}{|l|l|}
\hline Social Media Guide Component & Twitter Focus \\
\hline Audience focus & Undergraduate and graduate students \\
\hline Goals & Connect with students and build community \\
\hline Values & Availability, care, scholarship \\
\hline Activity focus & Information sharing; social interaction \\
\hline Tone \& tenor & Welcoming, warm, energetic \\
\hline Posting frequency & $\begin{array}{l}\text { Daily, with regular monitoring of subsequent } \\
\text { interactions }\end{array}$ \\
\hline Posting categories & Student life, local community \\
\hline Posting personnel & 1 librarian, approximately .10 FTE \\
\hline
\end{tabular}

Table 1. Social Media Activity Components

Prior to the formation of SMG, our Twitter activity featured automated posts that lacked a sense of presence and personality. After the formation of SMG, our Twitter activity featured hand-crafted posts that possessed both presence and personality. To measure the effectiveness of our social media program, we divided our Twitter activity into two categories based on the May 2012 date of SMG's formation: Phase 1 (Pre-SMG) and Phase 2 (Post-SMG). Phase 1 user data included followers 1-514, those users who followed the library between November 2008, when the library joined Twitter, and April 2012, the last month before the Library formed SMG. Phase 2 included followers 515-937, those users who followed the library between May 2012, when the library formed SMG, and August 2013, the end date of our research period. Using corresponding dates to our user analysis, Phase 1 Tweet data included the library's tweets 1-329, which were posted between November 2008 and April 2012, and Phase 2 included the library's tweets 330-998, which were posted between May 2012 and August 2013 (table 2). For the purposes of this research, Phase 1 and Phase 2 users and tweets were evaluated as distinct categories so that all corresponding tweets, followers, and interactions could be compared in relation to the formation date of SMG. Within Twitter, "followers" are members of the user community, "tweets" are 
messages to the community, and "interactions" are the user behaviors of favoriting, retweeting, or replying. Favorites are most commonly employed when users like a tweet. Favoriting a tweet can indicate approval, for instance. A user may also share another user's tweet with their own followers by "retweeting."

\begin{tabular}{|l|l|l|l|}
\hline & Followers & Tweets & Duration \\
\hline Phase 1 & $1-514$ & $1-329$ & Nov. 2008-April 2012 \\
\hline Phase 2 & $515-937$ & $330-998$ & May 2012-August 2013 \\
\hline
\end{tabular}

Table 2. Comparison of Phase 1 and 2 Twitter Activity

We employed three approaches for evaluating our Twitter activity: user type analysis, actionobject mapping, and interaction analysis. User type analysis aims to understand our community from a broad perspective by creating categories of users following the library's Twitter account. After reviewing the accounts of each member of our user community, we collected them into one of the following nine groups: alumni, business, community member, faculty, library, librarian, other, spam, and student. Categorization was based on a manual review of information found from each user's biographical profile, Tweet content, account name, and a comparison against campus directories.

Action-object mapping is a quantitative method that describes the relationship between the performance of an activity - the action-in relation to an external phenomenon-the object. Action-object mapping aims to describe the interaction process between a system and its users. ${ }^{54,55,56,57}$ Within the context of our study, the system is Twitter, the object is an individual tweet, and the action is the user behavior in response to the object, i.e., a user marking a tweet as a favorite, retweeting a tweet, or replying to a tweet. We collected our library's tweets into sixteen object categories: blog post, book, database, event, external web resource, librarian, library space, local community, other libraries/universities, photo from archive, topics-libraries, service, students, think tank, hortative, and workshop.

Interaction analysis serves as an extension of action-object mapping and aims to provide further details about the level of interaction between a system and its users. For this study we created an associated metric, "interaction rate," that measures the rate by which each object category received an action. Within the context of our study, we have treated the "action" of action-object mapping and the "interaction" of Twitter as equivalents. To identify the interaction rate, we used the following formula: "total number of Tweets within an object category" divided by "number of Tweets within an object category that received an action." Interaction rate was calculated for each object category and for all Tweets in Phase 1 and in Phase 2. 


\section{RESULTS}

The changes in approach to the library's Twitter presence through SMG and the Social Media Guide are evident in this study's results (figure 1). An analysis of user types in Phase 1 reveals a large portion, 48 percent, were business followers. In comparison, the business percentage decreased to 30 percent in Phase 2. The student percentage increased from 6 percent in Phase 1 to 28 percent in Phase 2, representing a 366 percent increase in student users. As noted earlier, the Social Media Guide Component, "audience focus" for Twitter is "undergraduate and graduate students" and includes the "goal" to "connect with students and build community" (table 1). The increase in the percentage of students in the follower population and the decrease in the business percentage of the population suggest progress towards this goal.

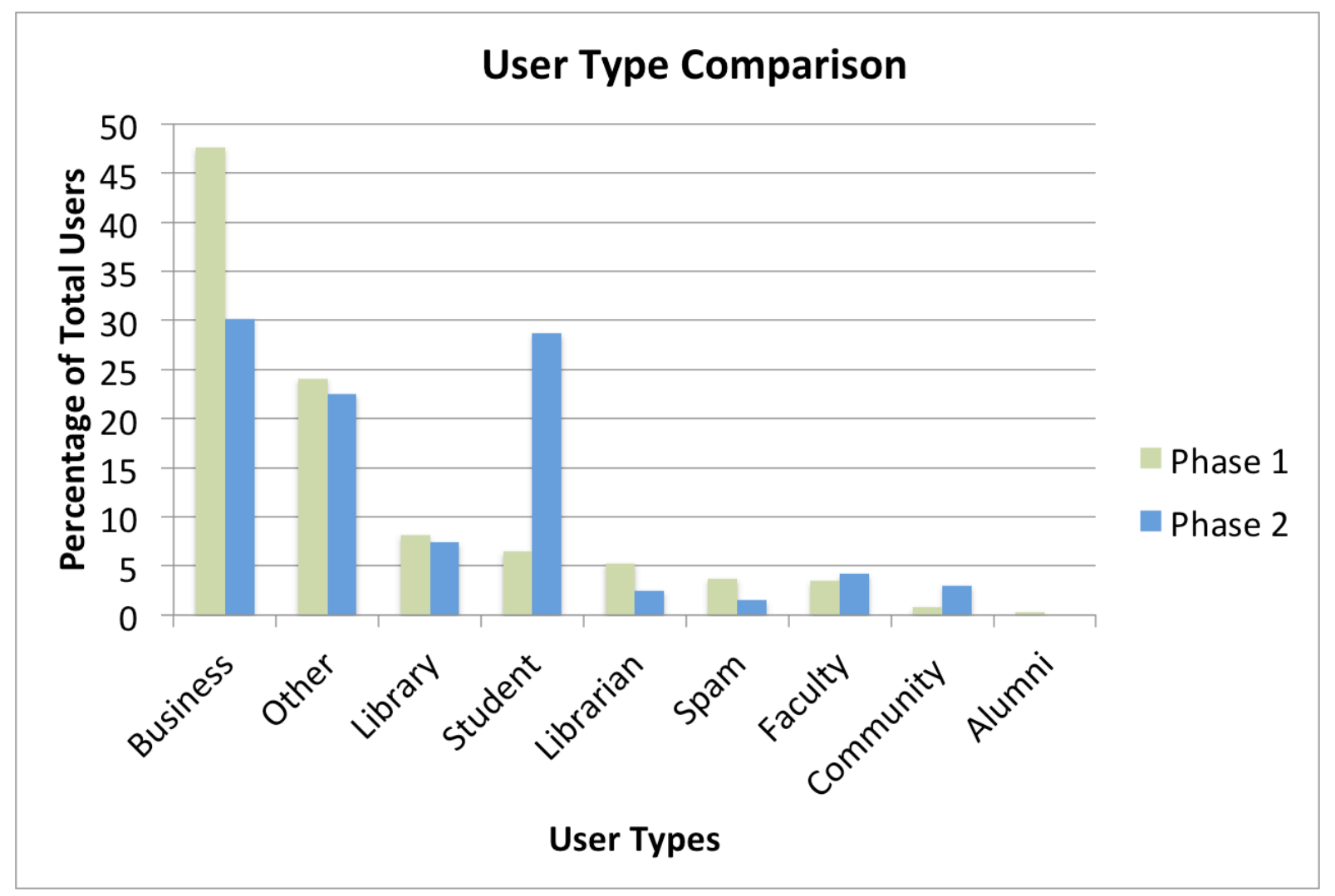

Figure 1. Comparison of Twitter Users by Type

The object categorization for Phase 1 shows a heavily skewed distribution of tweets in certain areas, while Phase 2 has a more even and targeted distribution reflecting implementation of the Social Media Guide components (figure 2). In Phase 1, workshops is the most Tweeted category with of 36 percent of all posts. Library space represents 18 percent of tweets while library events is third with 17 percent. The remaining 13 categories range from 5 percent to a fraction of a percent of tweets. Phase 2 shows a more balanced and intentional distribution of tweets across all object categories, with a strong focus on the Social Media Guide "posting category" of "student 
life," which accounted for 25 percent of tweets. Library Space consists of 11 percent of tweets, and external web resource composes 9 percent of tweets. The remaining categories range from 8 percent to 1 percent of tweets.

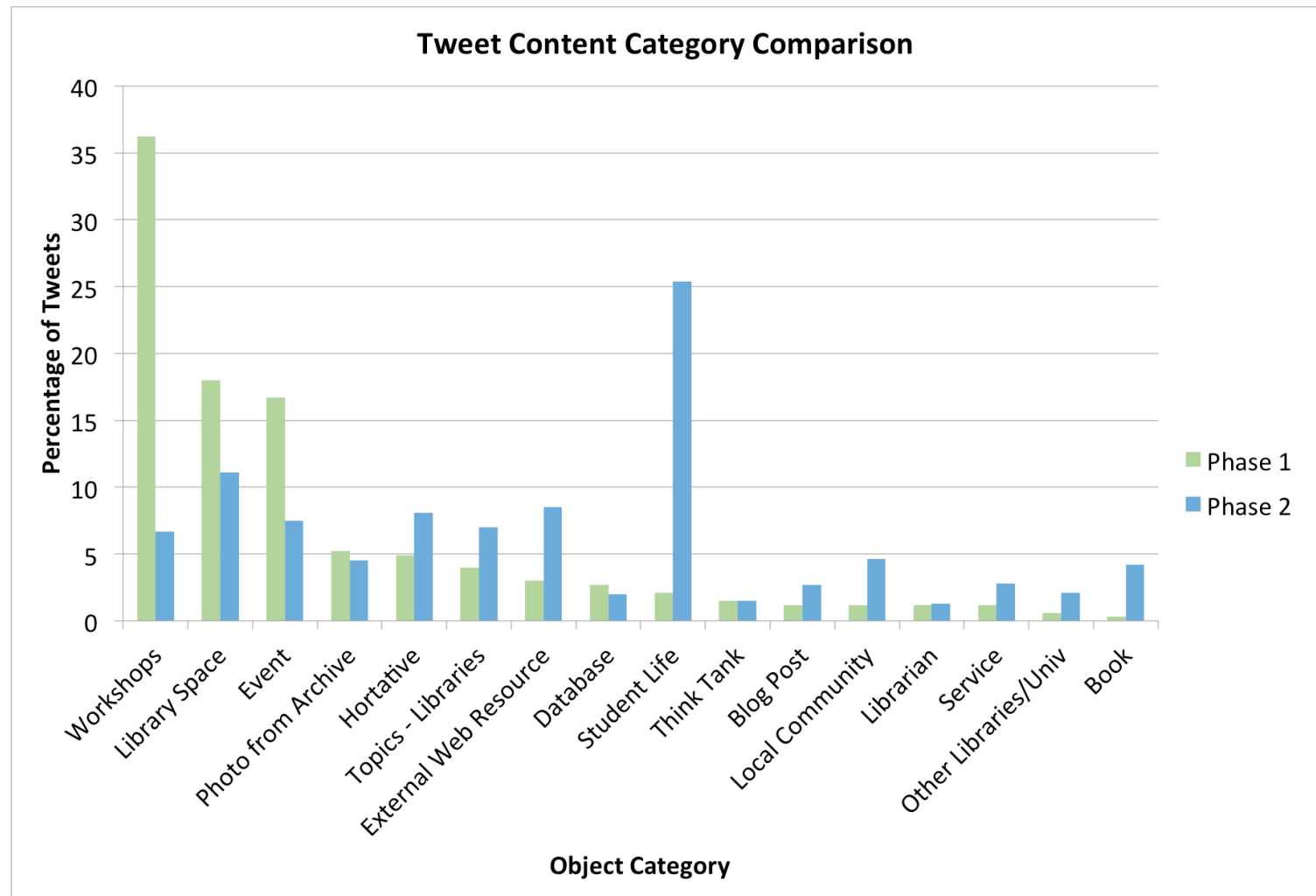

Figure 2. Comparison of Tweets by Content Category

Interaction rates were low in most object categories in Phase 1 (see figure 3). Given that the Social Media Guide has an "activity focus" of "social interaction," a tweet category with a high percentage of posting and a low interaction rate suggests a disconnect between tweet posting and meeting stated goals. For example, workshops represented a large percentage (36 percent) of the tweets but yielded a 0 percent interaction rate. Library space was 18 percent of tweets but had only a 2 percent interaction rate. Eleven of the 16 categories in Phase 1 had no associated actions and thus a 0 percent interaction rate. The interaction rate for Phase 1 was 12.5 percent. In essence, our action-object data and interaction rate data shows us that during Phase 1 we created content most frequently about topics of low interest to our community while we tweeted less frequently about topics of high interest to our community. 


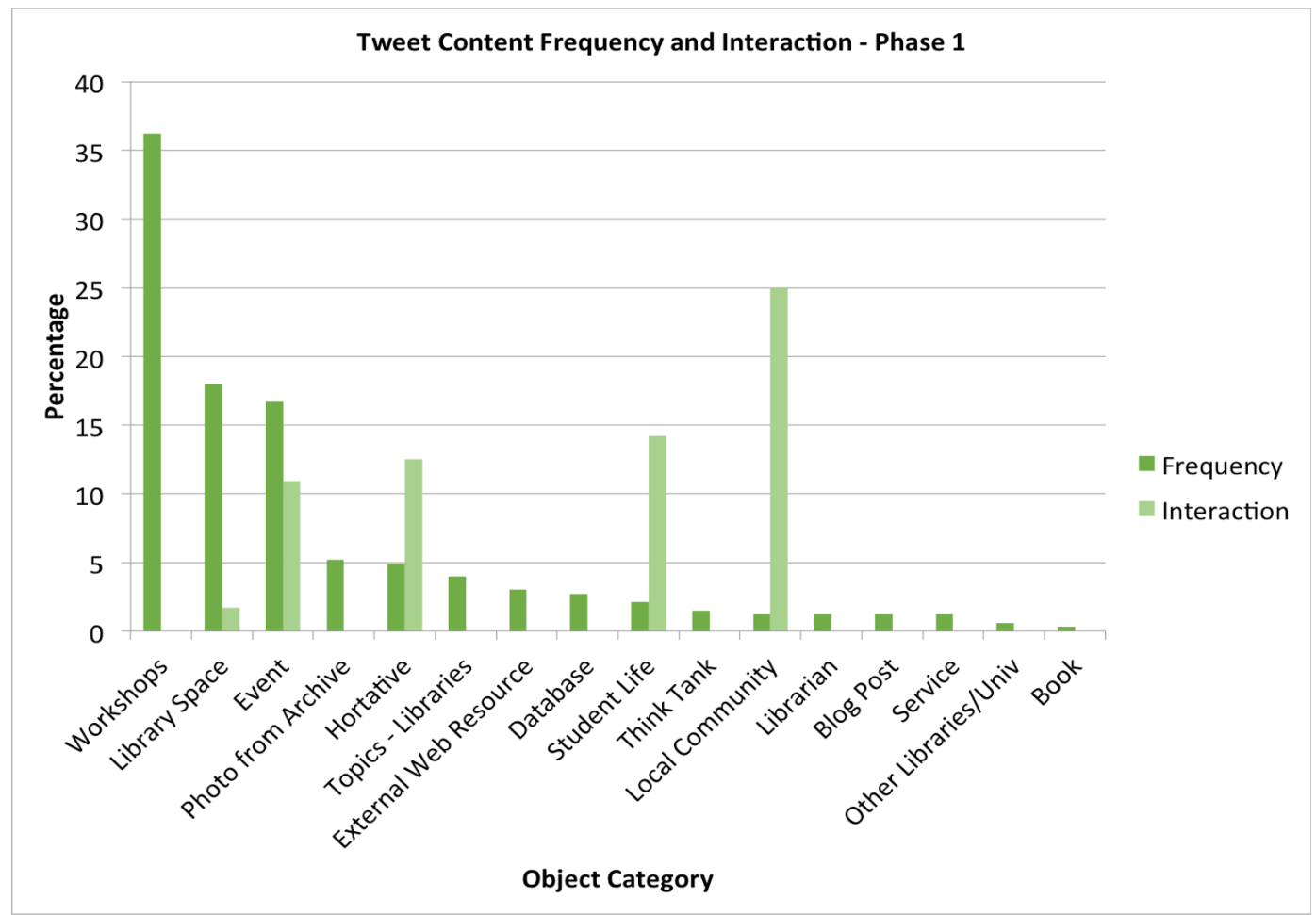

Figure 3. Interaction Rates, Phase 1

In contrast to Phase 1, Phase 2 interaction rate demonstrates an increase in interaction rate across nearly every object category (figure 4, figure 5), especially student life and local community.

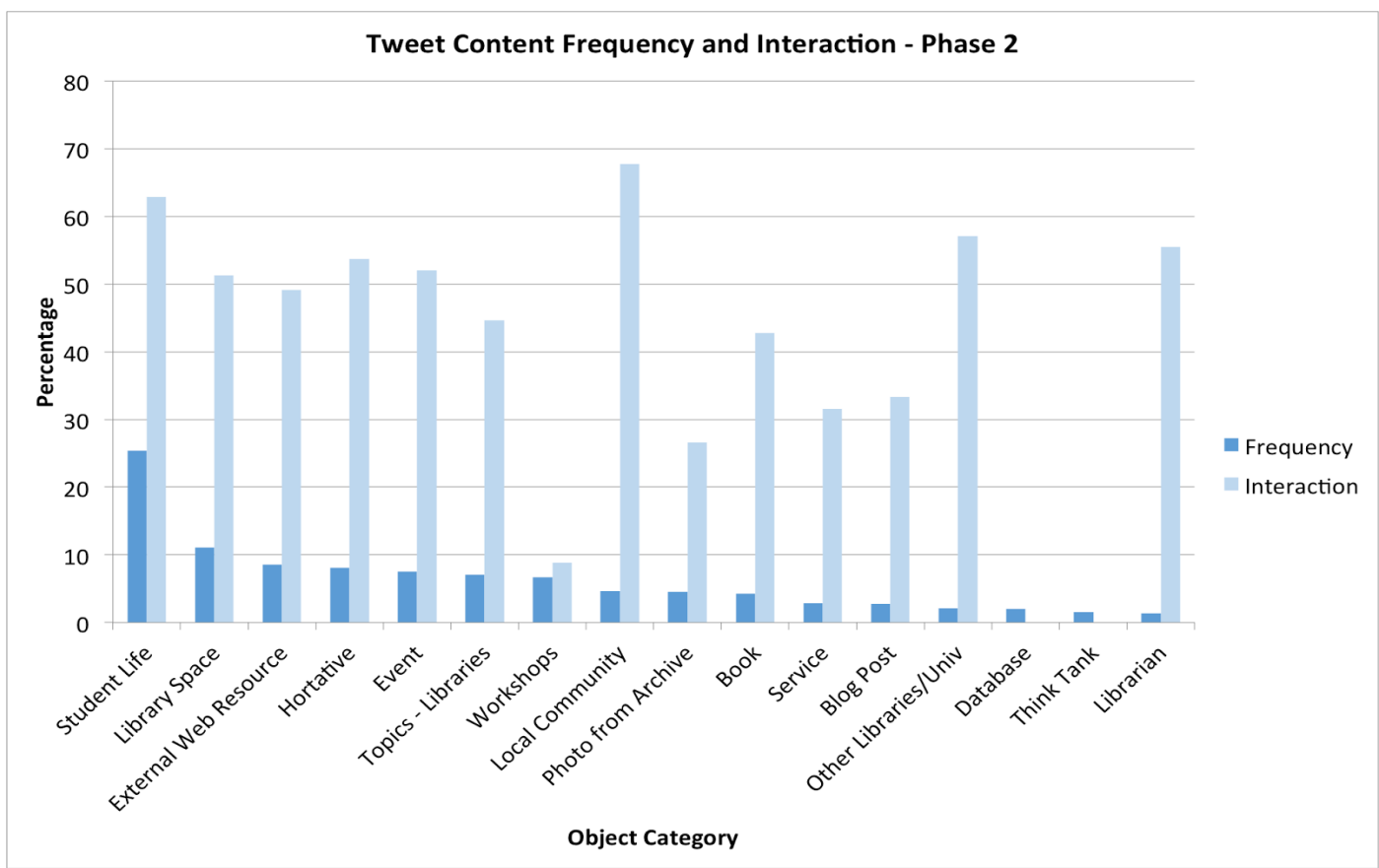

Figure 4. Interaction Rates, Phase 2 


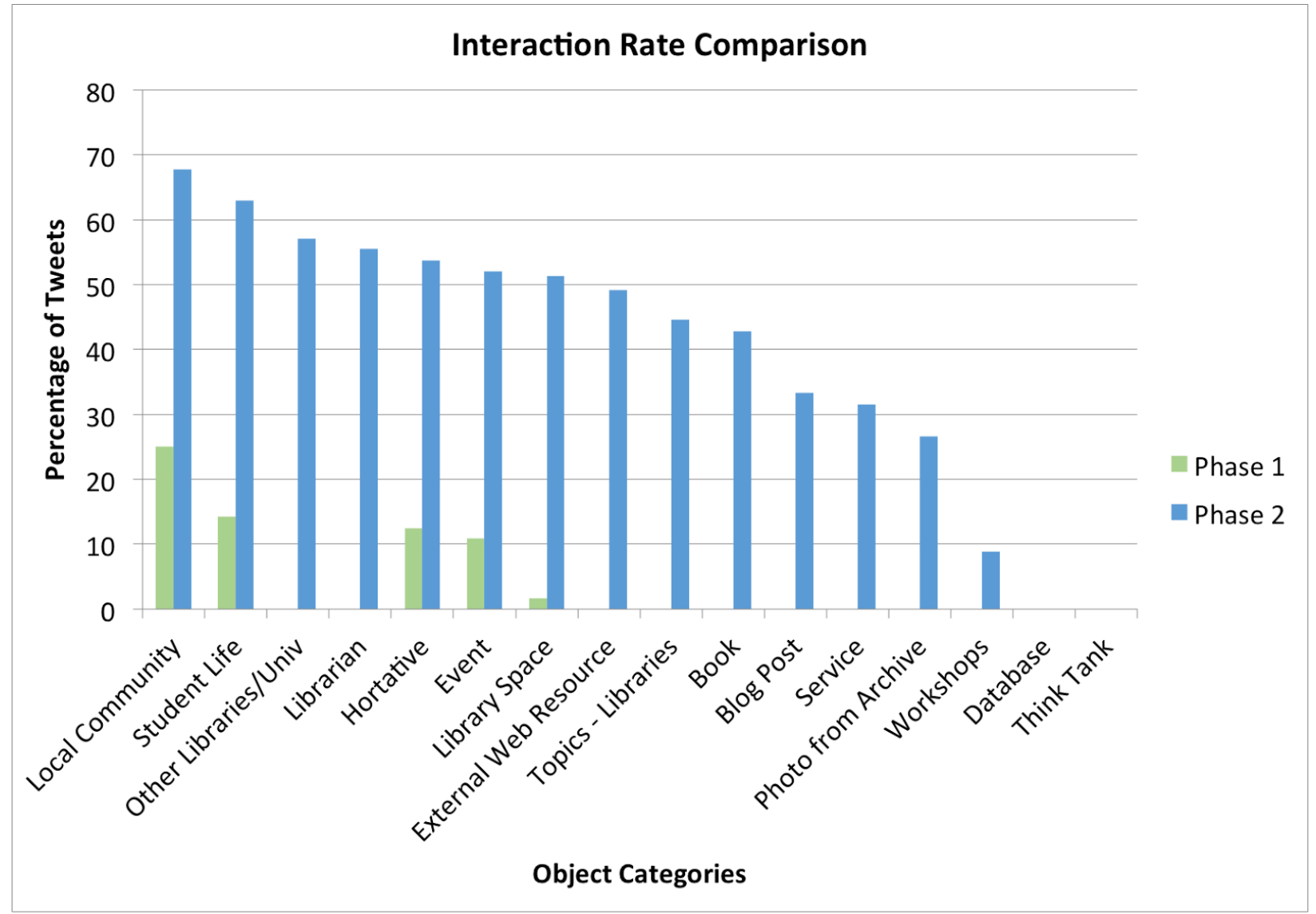

Figure 5. Interaction Rate Comparison

The local community category of tweets had the highest interaction rate at 68 percent. The student life category had the second highest interaction rate at 62 percent. Only 2 of the 16 categories in Phase 2 had no associated actions and thus a 0 percent interaction rate. The interaction rate for Phase 2 was 46.8 percent, which represented an increase of 275 percent from Phase 1. In essence, our action-object data and interaction rate data shows us that during Phase 2 we created content most frequently about topics of higher interest to our community while we tweeted less frequently about topics of low interest to our community.

\section{DISCUSSION}

This research suggests a strong community-building capability of social media at our academic library. The shift in user types from Phase 1 to Phase 2, notably the increase in student Twitter Followers, indicates that the shape of our Twitter community was directly affected by our social media program. Likewise, the marked increase in interaction rRate between Phase 1 and Phase 2 suggests the effectiveness of our programmatic community-focused approach.

The Montana State University Library social media program was fundamentally formed around an approach described by Glazer: "Be interesting, be interested."58 Our Twitter user community has thrived since we adopted this axiom. We have interpreted "interesting" as sharing original 
personality-rich content with our community and "interested" as regularly interacting with and responding to members of our community. The twofold theme of personality-rich content and interactivity-based behavior has allowed us to shape our Phase 2 user community.

Prior to the formation of SMG, social media at the MSU Library was a rather drab affair. The library Twitter account during that time was characterized by automated content, low responsiveness, no dedicated personnel, and no strategic vision. Our resulting Twitter community was composed of mostly businesses, at 47 percent of followers, with students representing just 6 percent of our followers. The resulting interaction rate of 12.5 percent reflects the broadcast-driven approach, personality-devoid content, and disengaged community that together characterized Phase 1.

Following the formation of SMG, the library Twitter account benefitted from original and unique content, high responsiveness, dedicated personnel, and a strategic, goal-driven vision. Our Phase 2 Twitter community underwent a transformation, with business representation decreasing to 30 percent and student representation increasing to 28 percent. The resulting interaction rate of 46.8 percent reflects our refocused community-driven program, personality-rich content, and engaged community of Phase 2 .

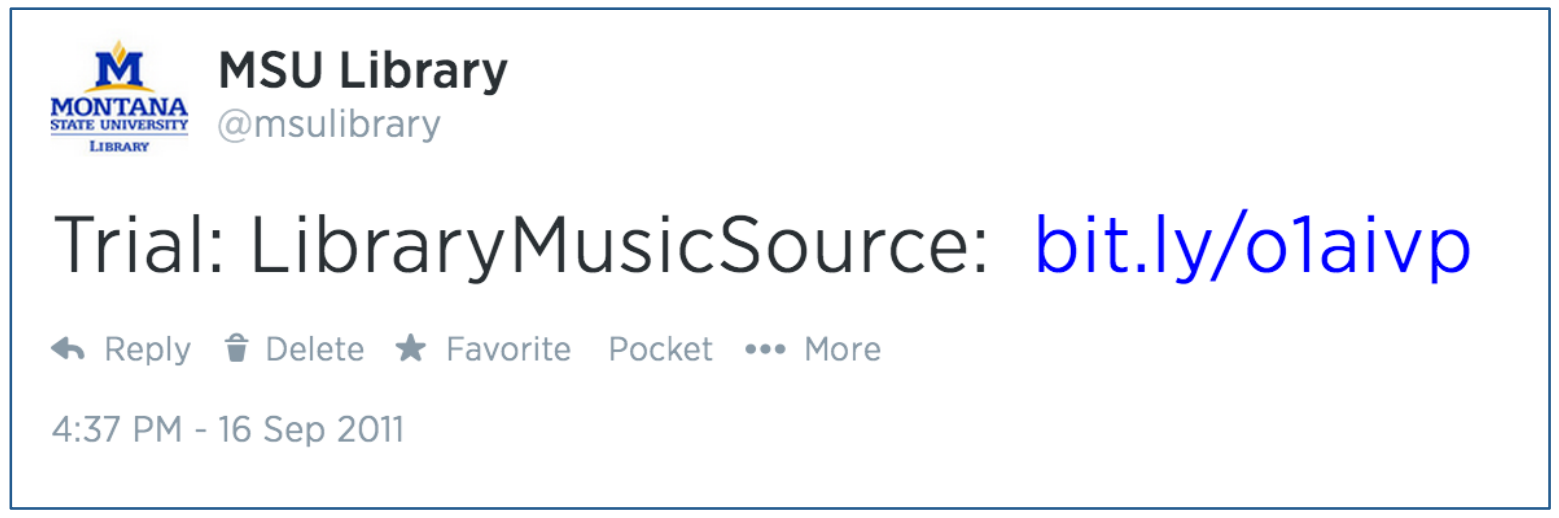

Figure 6. Typical Phase 1 Tweet

Figure 6 illustrates a typical Phase 1 Tweet. The object category for this tweet is database and it yielded no actions. The announcement of a new database trial was auto-generated from our library blog, a common method for sharing content during Phase 1 . This tweet is problematic for community-building for two primary reasons: the style and content lacks a sense and personality of a human author and does not offer compelling opportunities for interaction. 


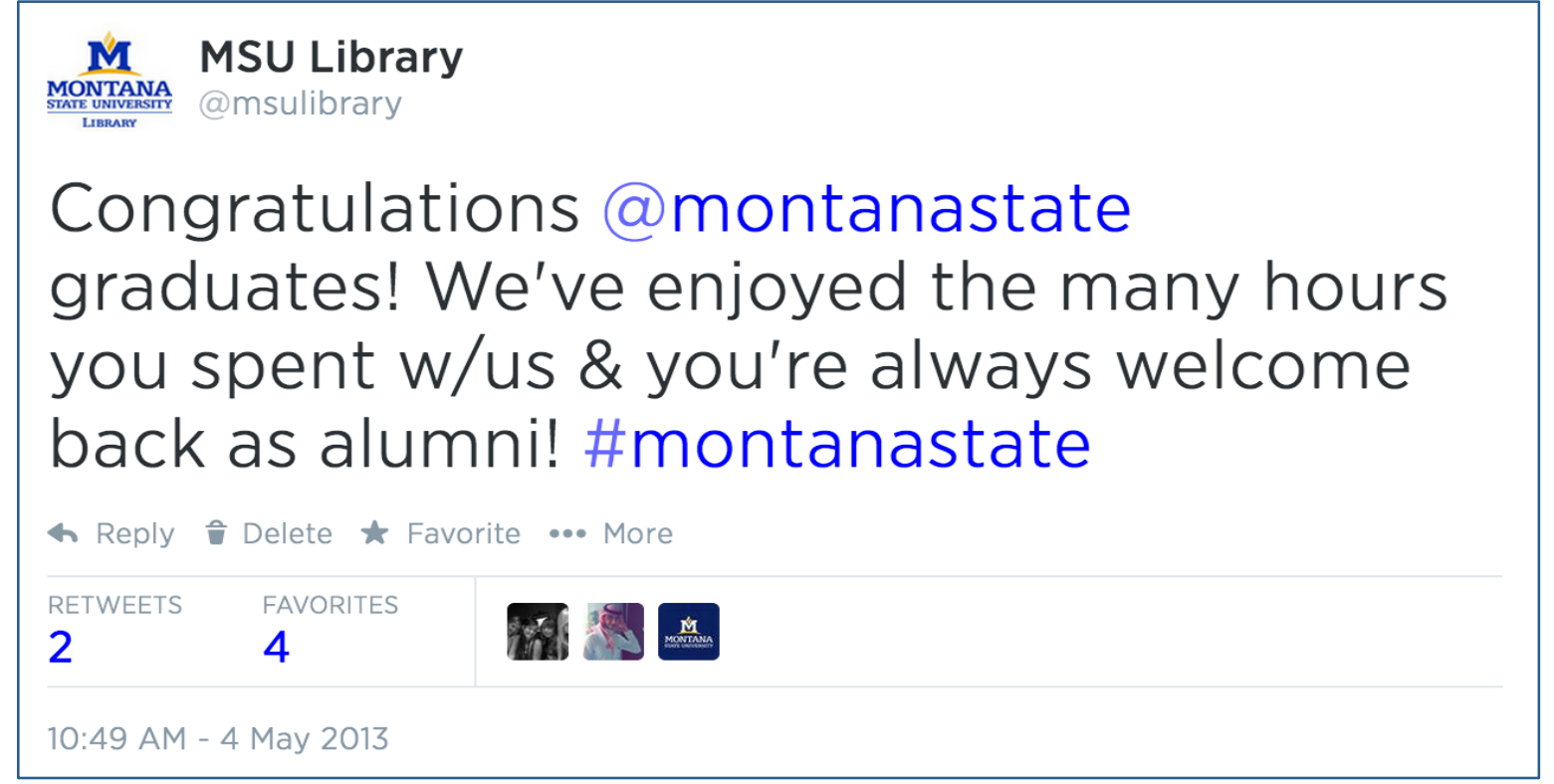

Figure 7. Typical Phase 2 Tweet

Figure 7 illustrates a typical Phase 2 Tweet. The object category for this tweet is student life and it yielded 6 actions ( 2 retweets and 4 favorites). The content relates to a meaningful and current event for our target student user community, and is fashioned in such a way as to invite interaction by providing a strong sense of relevancy and personality. Figure 8 further demonstrates the community effect of Phase 2. In this example we have reminded our Twitter community of the services available through the library, and one student user has replied. During our Phase 2 Twitter activity, we prioritized responsiveness, availability, and scholarship with the goal of connecting with students and building a sense of community. In many ways the series of tweets shown in figure 8 encapsulates our social media program. We were able to deliver resources to this student, who then associates these interactions with a sense of pride in the university. This example illustrates the overall connectedness afforded by social media. In contacting the Library Twitter account, this user asked a real-world research question. Neither his inquiry nor our response was located strictly within an online world. While we pointed this user to an online resource, his remarks indicated "offline" feelings of satisfaction with the interaction. Lee and Oh found that social media interactivity and information sharing can create a shared vision that leads to a sense of community belonging. ${ }^{59,60}$ By creating personality-rich content that invites two-way interaction, our strategic social media program has helped form a holistic community of users around our Twitter activity. 


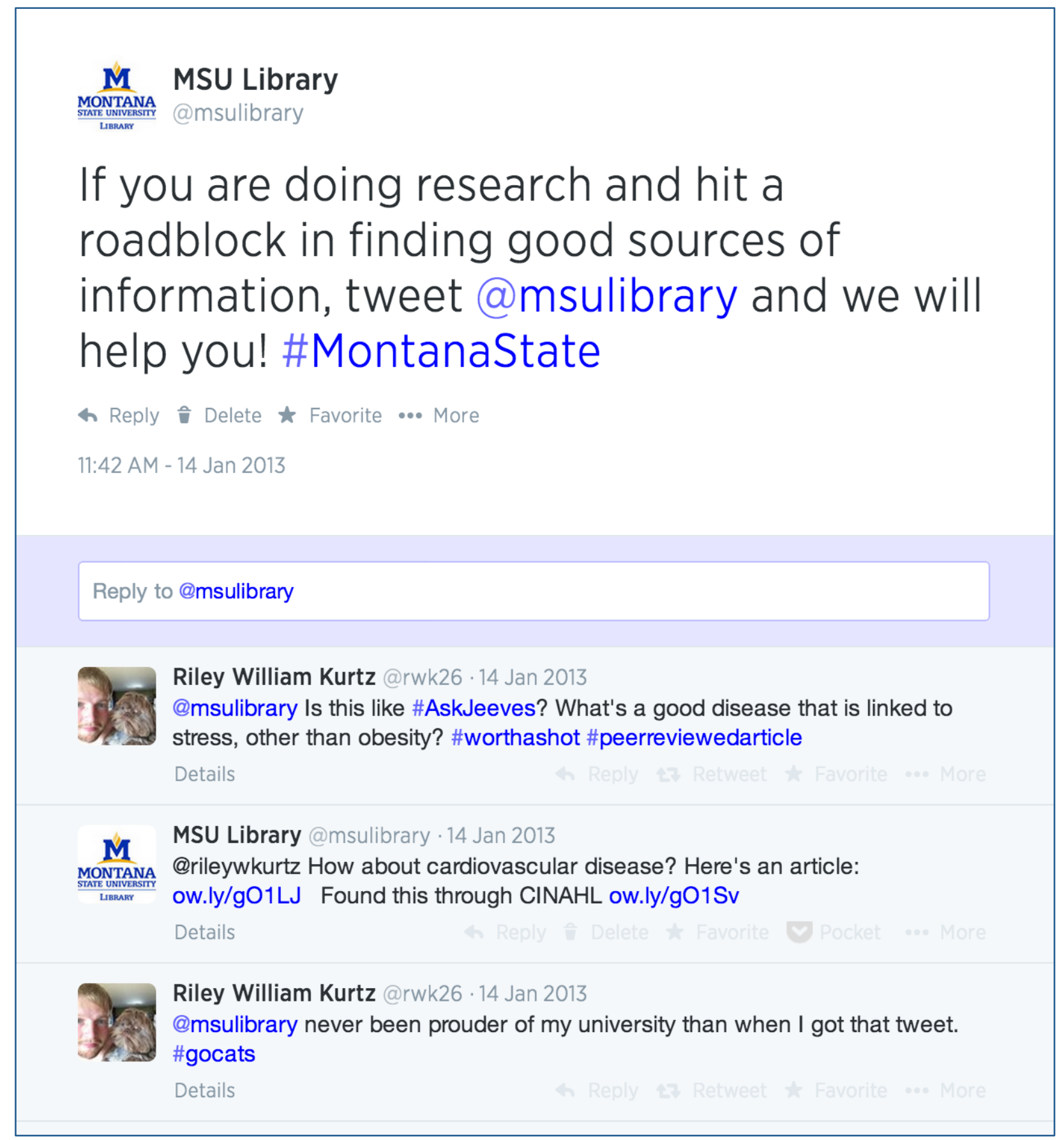

Figure 8. Phase 2 Example, Community Effect

Currently our work addresses the formation of community through social media. A next step will introduce a wider scope by addressing the value of community formed through social media. There is a rich area of study around the relationship between social media activity, perceived sense of community and connectedness, and student success. 61,62,63,64,65 Further research along this line will allow us to explore whether a library-led social media community can serve as an aid in undergraduate academic performance and graduation rate. Continued and extended analysis 
will allow us to increase the granularity of results, for example by mapping user types to actionobject pairs and identifying the interaction rate for particular users such as students and faculty.

\section{CONCLUSION}

In articulating and realizing an intentional and strategic social media program, we have generated results that demonstrate the community-building capability of social media. Over the course of one year, we transformed our social media activity from personality-devoid one-way broadcasting to personality-rich two-way interacting. The research that followed this fundamental shift provided new information about our users that enabled us to tailor our Twitter activity and shape our community around a target population of undergraduate students. In so doing, we have formed a community that has shown new interest in social media content published by the library. Following the application of our social media program, our student user community grew by 366 percent and the rate of interaction with our community grew by 275 percent. Our research demonstrates the value of social media as a community-building tool, and our model can guide social media in libraries toward this purpose.

\section{REFERENCES}

1. Harry Glazer, "Clever Outreach or Costly Diversion? An Academic Library Evaluates Its Facebook experience," College \& Research Libraries News 70, no. 1 (2009): 11, http://crln.acrl.org/content/70/1/11.full.pdf+html.

2. Harry Glazer, "Likes' are Lovely, but Do They Lead to More Logins? Developing Metrics for Academic Libraries' Facebook pages," College \& Research Libraries News 73, no. 1 (2012): 20, http://crln.acrl.org/content/73/1/18.full.pdf+html.

3. Lee A. Vucovich et al., "Is the Time and Effort Worth It? One Library's Evaluation of Using Social Networking Tools for Outreach," Medical Reference Services Quarterly 32, no. 1 (2013): 13, http://dx.doi.org/10.1080/02763869.2013.749107.

4. Xiang Li and Tang Li, "Integrating Social Media into East Asia Library Services: Case Studies at University of Colorado and Yale University," Journal of East Asian Libraries 157, no. 1 (2013): 24, https://ojs.lib.byu.edu/spc/index.php/JEAL/article/view/32663/30799.

5. Colleen Cuddy, Jamie Graham, and Emily G. Morton-Owens, "Implementing Twitter in a Health Sciences Library," Medical Reference Services Quarterly 29, no. 4 (2010), http://dx.doi.org/10.1080/02763869.2010.518915.

6. Steven Bell, "Students Tweet the Darndest Things about Your Library-And Why You Need to Listen," Reference Services Review 40, no. 2 (2012), http://dx.doi.org/10.1108/00907321211228264. 
7. Robin R. Sewell, "Who is Following Us? Data Mining a Library's Twitter Followers," Library Hi Tech 31, no. 1 (2013), http://dx.doi.org/10.1108/07378831311303994.

8. Li and Li, "Integrating Social Media into East Asia Library Services," 25.

9. Remi Castonguay, "Say It Loud Spreading the Word with Facebook and Twitter," College \& Research Libraries News 72, no. 7 (2011), http://crln.acrl.org/content/72/7/412.full.pdf+html.

10. Dianna E. Sachs, Edward J. Eckel, and Kathleen A. Langan, "Striking a Balance: Effective Use of Facebook in an Academic Library," Internet Reference Services Quarterly 16, nos. 12 (2011), http://dx.doi.org/10.1080/10875301.2011.572457.

11. Christopher Chan, "Marketing the Academic Library with Online Social Network Advertising," Library Management 33, no. 8, (2012), http://dx.doi.org/10.1108/01435121211279849.

12. Melissa Dennis, "Outreach Initiatives in Academic Libraries, 2009-2011," Reference Services Review 40, no. 3, (2012), http://dx.doi.org/10.1108/00907321211254643.

13. Melanie Griffin and Tomaro I. Taylor, "Of Fans, Friends, and Followers: Methods for Assessing Social Media Outreach in Special Collections Repositories," Journal of Web Librarianship 7, no. 3 (2013), http://dx.doi.org/10.1080/19322909.2013.812471.

14. Lili Luo, "Marketing via Social Media: A Case Study,” Library Hi Tech 31, no. 3 (2013), http://dx.doi.org/10.1108/LHT-12-2012-0141.

15. Li and Li, "Integrating Social Media into East Asia Library Services,” 25.

16. Sachs, Eckel, and Langan, "Striking a Balance," 48.

17. Jaana Roos, "Why University Libraries Don't Trust Facebook Marketing?," Proceedings of the 21st International BOBCATSSS Conference (2013): 164, http://bobcatsss2013.bobcatsss.net/proceedings.pdf.

18. Noa Aharony, "Twitter Use in Libraries: An Exploratory Analysis," Journal of Web Librarianship 4, no. 4 (2010), http://dx.doi.org/10.1080/19322909.2010.487766.

19. A. R. Riza Ayu and A. Abrizah, "Do You Facebook? Usage and Applications of Facebook Page among Academic Libraries in Malaysia," International Information \& Library Review 43, no. 4 (2011), http://dx.doi.org/10.1016/j.iilr.2011.10.005.

20. Alton Y. K. Chua and Dion H Goh., "A Study of Web 2.0 Applications in Library Websites," Library \& Information Science Research 32, no. 3 (2010), http://dx.doi.org/10.1016/j.lisr.2010.01.002. 
21. Andrea Dickson and Robert P. Holley, "Social Networking in Academic Libraries: The Possibilities and the Concerns," New Library World 111, nos. 11/12 (2010), http://dx.doi.org/10.1108/03074801011094840.

22. Valerie Forrestal, "Making Twitter Work: a Guide for the Uninitiated, the Skeptical, and the Pragmatic," Reference Librarian 52, nos. 1-2 (2010), http://dx.doi.org/10.1080/02763877.2011.527607.

23. Gang Wan, "How Academic Libraries Reach Users on Facebook," College \& Undergraduate Libraries 18, no. 4 (2011), http://dx.doi.org/10.1080/10691316.2011.624944.

24. Dora Yu-Ting Chen, Samuel Kai-Wah Chu, and Shu-Qin Xu, "How Do Libraries Use Social Networking Sites to Interact with Users," Proceedings of the American Society for Information Science and Technology 49, no. 1 (2012), http://dx.doi.org/10.1002/meet.14504901085.

25. Rolando Garcia-Milian, Hannah F. Norton, and Michele R. Tennant, "The Presence of Academic Health Sciences Libraries on Facebook: The Relationship between Content and Library Popularity," Medical Reference Services Quarterly 31, no. 2 (2012), http://dx.doi.org/10.1080/02763869.2012.670588.

26. Elaine Thornton, "Is Your Academic Library Pinning? Academic Libraries and Pinterest," Journal of Web Librarianship 6, no. 3 (2012), http://dx.doi.org/10.1080/19322909.2012.702006.

27. Katie Elson Anderson and Julie M. Still, “Librarians' Use of Images on LibGuides and Other Social Media Platforms," Journal of Web Librarianship 7, no. 3 (2013), http://dx.doi.org/10.1080/19322909.2013.812473.

28. Grace Saw, "Social Media for International Students-It's Not All about Facebook," Library Management 34, no. 3 (2013): 172, http://dx.doi.org/10.1108/01435121311310860.

29. Ligaya Ganster and Bridget Schumacher, "Expanding Beyond Our Library Walls: Building an Active Online Community through Facebook," Journal of Web Librarianship 3, no. 2 (2009), http://dx.doi.org/10.1080/19322900902820929.

30. Sebastián Valenzuela, Namsu Park, and Kerk F. Kee, "Is There Social Capital in a Social Network Site? Facebook Use and College Students' Life Satisfaction, Trust, and Participation," Journal of Computer-Mediated Communication 14, no. 4 (2009), http://dx.doi.org/10.1111/j.1083-6101.2009.01474.x.

31. Nancy Kim Phillips, "Academic Library Use of Facebook: Building Relationships with Students," Journal of Academic Librarianship 37, no. 6 (2011), http://dx.doi.org/10.1016/j.acalib.2011.07.008. 
32. Tina McCorkindale, Marcia W. Distaso, and Hilary Fussell Sisco, "How Millennials Are Engaging and Building Relationships with Organizations on Facebook," Journal of Social Media in Society 2, no. 1 (2013), http://thejsms.org/index.php/TSMRI/article/view/15/18.

33. Valenzuela, Park, and Kee, “Is There Social Capital in a Social Network Site?," 882.

34. Maria R. Lee, David C. Yen, and C. Y. Hsiao, "Understanding the Perceived Community Value of Facebook Users," Computers in Human Behavior 35 (February 2014): 355, http://dx.doi.org/10.1016/j.chb.2014.03.018.

35. Hyun Jung Oh, Elif Ozkaya, and Robert LaRose, "How Does Online Social Networking Enhance Life Satisfaction? The Relationships among Online Supportive Interaction, Affect, Perceived Social Support, Sense of Community, and Life Satisfaction," Computers in Human Behavior 30 (2014), http://dx.doi.org/10.1016/j.chb.2013.07.053.

36. Rowena Cullen and Laura Sommer, "Participatory Democracy and the Value of Online Community Networks: An Exploration of Online and Offline Communities Engaged in Civil Society and Political Activity," Government Information Quarterly 28, no. 2 (2011), http://dx.doi.org/10.1016/j.giq.2010.04.008.

37. Mohamed Nanabhay and Roxane Farmanfarmaian, "From Spectacle to Spectacular: How Physical Space, Social Media and Mainstream Broadcast Amplified the Public Sphere in Egypt's 'Revolution,'” Journal of North African Studies 16, no. 4 (2011), http://dx.doi.org/10.1080/13629387.2011.639562.

38. Nermeen Sayed, "Towards the Egyptian Revolution: Activists Perceptions of Social Media for Mobilization," Journal of Arab \& Muslim Media Research 4, nos. 2-3 (2012): 273-98, http://dx.doi.org/10.1386/jammr.4.2-3.273_1.

39. Morton A. Lieberman and Andrew Winzelberg, "The Relationship between Religious Expression and Outcomes in Online Support Groups: A Partial Replication," Computers in Human Behavior 25, no. 3 (2009), http://dx.doi.org/10.1016/j.chb.2008.11.003.

40. Christopher E. Beaudoin and Chen-Chao Tao, "Benefiting from Social Capital in Online Support Groups: An Empirical Study of Cancer Patients," Cyberpsychology \& Behavior: The Impact of the Internet, Multimedia and Virtual Reality on Behavior and Society 10, no. 4 (2007), http://dx.doi.org/10.1089/cpb.2007.9986.

41. Manuela Tomai et al., "Virtual Communities in Schools as Tools to Promote Social Capital with High Schools Students," Computers \& Education 54, no. 1 (2010), http://dx.doi.org/10.1016/j.compedu.2009.08.009. 
42. Edward Shih-Tse Wang and Lily Shui-Lien Chen, "Forming Relationship Commitments to Online Communities: The Role of Social Motivations," Computers in Human Behavior 28, no. 2 (2012), http://dx.doi.org/10.1016/j.chb.2011.11.002.

43. Pippa Norris and David Jones, "Virtual Democracy," Harvard International Journal of Press/Politics 3, no. 2 (1998), http://dx.doi.org/10.1177/1081180X98003002001.

44. Xu Cheng, Jiangchuan Liu, and Cameron Dale, "Understanding the Characteristics of Internet Short Video Sharing: A YouTube-Based Measurement Study," IEEE Transactions on Multimedia 15, no. 5 (2013), http://dx.doi.org/10.1109/TMM.2013.2265531.

45. Nancy Foasberg, “Online Reading Communities: From Book Clubs to Book Blogs,” Journal of Social Media in Society 1, no.1 (2012), http://thejsms.org/index.php/TSMRI/article/view/3/4.

46. Matthias Hofer and Viviane Aubert, "Perceived Bridging and Bonding Social Capital of Twitter: Differentiating between Followers and Followees," Computers in Human Behavior 29, no. 6 (2013): 2137, http://dx.doi.org/10.1016/j.chb.2013.04.038.

47. Rachel Grieve et. al., "Face-to-Face or Facebook: Can Social Connectedness be Derived Online?," Computers in Human Behavior 29, no. 3 (2013): 607, http://dx.doi.org/10.1016/j.chb.2012.11.017.

48. Ibid., 608.

49. Nathan Jurgenson, "When Atoms Meet Bits: Social Media, the Mobile Web and Augmented Revolution,” Future Internet 4, no. 1 (2012), http://dx.doi.org/10.3390/fi4010083.

50. R. Stuart Geiger, "Bots, Bespoke, Code and the Materiality of Software Platforms," Information, Communication \& Society 17, no. 3 (2014), http://dx.doi.org/10.1080/1369118X.2013.873069.

51. Zeynep Tufekci, "The Social Internet: Frustrating, Enriching, but Not Lonely," Public Culture 26, no. 1, iss. 72 (2013): 14, http://dx.doi.org/10.1215/08992363-2346322.

52. Nicole B. Ellison, Charles Steinfield, and Cliff Lampe, "The Benefits of Facebook 'Friends': Social Capital and College Students' Use of Online Social Network Sites," Journal of Computer-Mediated Communication 12, no. 4 (2007): 1144, http://dx.doi.org/10.1111/j.1083-6101.2007.00367.x.

53. Ibid., 1165.

54. Roger Brown, A First Language: The Early Stages (Cambridge: Harvard University Press, 1973). 
55. Mimi Zhang and Bernard J. Jansen, "Using Action-Object Pairs as a Conceptual Framework for Transaction Log Analysis," in Handbook of Research on Web Log Analysis, edited by Bernard J. Jansen, Amanda Spink, and Isak Taksa (Hershey, PA: IGI, 2008).

56. Bernard J. Jansen and Mimi Zhang, "Twitter Power: Tweets as Electronic Word of Mouth," Journal of the American Society for Information Science \& Technology 60, no. 11 (2009), http://dx.doi.org/10.1002/asi.v60:11.

57. Sewell, "Who is Following Us?"

58. Glazer, "Likes' are Lovely," 20.

59. Lee, Yen, and Hsiao, "Understanding the Perceived."

60. Oh, Ozkaya, and LaRose, "How Does Online Social Networking."

61. Reynol Junco, Greg Heiberger, and Eric Loken, "The Effect of Twitter on College Student Engagement and Grades," Journal of Computer Assisted Learning 27, no. 2 (2011), http://dx.doi.org/10.1111/j.1365-2729.2010.00387.x.

62. Susannah K. Brown and Charles A. Burdsal, "An Exploration of Sense of Community and Student Success Using the National Survey of Student Engagement," Journal of General Education 61, no. 4 (2012), http://dx.doi.org/10.1353/ige.2012.0039.

63. Jill L. Creighton et al., "I Just Look It Up: Undergraduate Student Perception of Social Media Use in Their Academic Success," Journal of Social Media in Society 2, no. 2 (2013), http://thejsms.org/index.php/TSMRI/article/view/48/25.

64. David C. DeAndrea et al., "Serious Social Media: On the Use of Social Media for Improving Students' Adjustment to College," The Internet and Higher Education 15, no. 1 (2012), http://dx.doi.org/10.1016/j.iheduc.2011.05.009.

65. Rebecca Gray et al., "Examining Social Adjustment to College in the Age of Social Media: Factors Influencing Successful Transitions and Persistence," Computers \& Education 67 (2013), http://dx.doi.org/10.1016/j.compedu.2013.02.021. 